\title{
Newly Emerged Populations of Plasmopara halstedii Infecting Rudbeckia Exhibit Unique Genotypic Profiles and Are Distinct from Sunflower- Infecting Strains
}

\author{
Yazmín Rivera, Catalina Salgado-Salazar, Thomas J. Gulya, and Jo Anne Crouch
}

First, second, and fourth author: U.S. Department of Agriculture-Agriculture Research Service (USDA-ARS), Systematic Mycology and Microbiology Laboratory, 10300 Baltimore Avenue, Beltsville, MD 20705; first and second authors: Department of Plant Biology and Pathology, Rutgers University, 59 Dudley Road, New Brunswick, NJ 08906; and third author: USDA-ARS, Sunflower and Plant Biology Research Unit, 1605 Albrecht Boulevard North, Fargo, ND 58102 (retired).

Accepted for publication 12 March 2016.

\begin{abstract}
Rivera, Y., Salgado-Salazar, C., Gulya, T. J., and Crouch, J. A. 2016. Newly emerged populations of Plasmopara halstedii infecting rudbeckia exhibit unique genotypic profiles and are distinct from sunflowerinfecting strains. Phytopathology 106:752-761.

The oomycete Plasmopara halstedii emerged at the onset of the 21st century as a destructive new pathogen causing downy mildew disease of ornamental Rudbeckia fulgida (rudbeckia) in the United States. The pathogen is also a significant global problem of sunflower (Helianthus annuus) and is widely regarded as the cause of downy mildew affecting 35 Asteraceae genera. To determine whether rudbeckia and sunflower downy mildew are caused by the same genotypes, population genetic and phylogenetic analyses were performed. A draft genome assembly

sequenced phylogenetic markers measured differentiation between 232 P. halstedii samples collected from 1883 to 2014. Samples clustered into two main groups, corresponding to host origin. Sunflower-derived samples separated into eight admixed subclusters, and rudbeckiaderived samples further separated into three subclusters. Pre-epidemic rudbeckia samples clustered separately from modern strains. Despite the observed genetic distinction based on host origin, $P$. halstedii from rudbeckia could infect sunflower, and exhibited the virulence phenotype of race 734 . These data indicate that the newly emergent pathogen populations infecting commercial rudbeckia are a different species from sunflower-infecting strains, notwithstanding cross-infectivity, and genetically distinct from pre-epidemic populations infecting native rudbeckia hosts.
\end{abstract} of a $P$. halstedii isolate from sunflower was generated and used to design 15 polymorphic simple sequence repeat (SSR) markers. SSRs and two

Downy mildew diseases affecting Asteraceae hosts are found worldwide and are responsible for major economic losses to the oilseed and ornamental industries (Constantinescu and Thines 2010; Farr and Rossman 2015; Gulya et al. 1997). Plasmopara halstedii was first described as Peronospora halstedii on Eupatorium purpureum (sweet-scented Joe Pye weed) and six additional Asteraceae hosts: Ambrosia artemisifolia, Bidens frondosa, Helianthus strumosus, Rudbeckia laciniata, and Silphium terebinthaceum (Farlow 1883). Following these early reports, any Plasmopara infecting plants in the Asteraceae family was regarded as $P$. halstedii, irrespective of observed morphological variation (Leppik 1966). Today, at least 35 different plant genera within the Asteroideae and Chicorideae subfamilies are reported as hosts to P. halstedii (Leppik 1966; Sackston 1981). Support for $P$. halstedii as a morphologically diverse species with a wide host range has come from several studies that show susceptibility of cultivated sunflower (H. annuus) to strains originating from other Asteraceae host genera, including Ambrosia, Dimorphotheca, Iva, and Xanthium (Gulya 2002; Komjáti et al. 2007; Leppik 1965; Viranyi 1984; Walcz et al. 2000). However, the presumed host range of $P$. halstedii sensu stricto is an ongoing subject of discussion, with many regarding the pathogen as a species

Corresponding author: J. A. Crouch; E-mail address: joanne.crouch@ars.usda.gov

*The $\boldsymbol{e}$-Xtra logo stands for "electronic extra" and indicates that four supplementary figures and four supplementary tables are published online.

http://dx.doi.org/10.1094/PHYTO-12-15-0335-R

This article is in the public domain and not copyrightable. It may be freely reprinted with customary crediting of the source. The American Phytopathological Society, 2016.
Additional keyword: microsatellites.

complex rather than a single species (Choi et al. 2009; Göker et al. 2007; Schröder et al. 2011; Thines et al. 2009). Several recent studies have identified discrete Plasmopara species on Asteraceae hosts that are genetically and/or morphologically distinct from $P$. halstedii. These include $P$. angustiterminalis on $X$. strumarium, $P$. invertifolia on Helichrysum bracteatum, and an unnamed species infecting A. artemisifolia (Choi et al. 2009; Duarte et al. 2014; Komjáti et al. 2007).

Beginning in 2004, the emergence of $P$. halstedii as a destructive new pathogen of the ornamental plant $R$. fulgida (rudbeckia) in the United States brought this organism to the attention of the nursery and landscape industry (Dankers et al. 2004; Hong 2006; Rivera et al. 2014). This low-maintenance perennial plant is highly valued for its extended flowering period, beautiful flowers, and the absence of any significant pest or pathogen problems. Over 3.8 million rudbeckia plants are sold annually in the United States alone, valued at $\$ 13$ million (2007 Census of Horticultural Specialties, USDA, National Agricultural Statistics Service, issued December 2010; http://www.agcensus.usda.gov). Rudbeckia downy mildew (RDM) disease caused by $P$. halstedii is characterized by dark purple lesions on leaves and profuse white sporangial masses on the abaxial surface (Rivera et al. 2015a). Under conducive environmental conditions, RDM can be so severe that commercial greenhouses and nurseries can lose an entire year's crop (Hong 2006). The emergence of this disease represents a substantial threat to the commercial nursery and landscape industry.

The emergence of $P$. halstedii as a problematic issue for rudbeckia represents just one of several new downy mildew disease outbreaks to affect specialty crops in the United States and worldwide during the past decade (Cohen et al. 2015; Crouch et al. 
2013; Daughtrey et al. 2006; Rivera et al. 2015a; Thines et al. 2009). Destructive new downy mildews currently impede production of mainstay specialty crops such as impatiens, basil, coleus, hyssops, and cucurbits (Crouch et al. 2013; Daughtrey et al. 2006; Rivera et al. 2015b; Rivera et al. 2016; Thines et al. 2009). However, 10 to 15 years previous, damage to these plants due to downy mildews was virtually unknown, or as in the case of cucurbits, well controlled through resistant cultivars (Cohen et al. 2015). Also in common with other emergent downy mildews of specialty crops, the factors underlying the emergence of RDM remain a mystery. As seen in other newly emergent downy mildew pathosystems (e.g., impatiens and cucurbits), there are several pre-epidemic records of $P$. halstedii inhabiting native Rudbeckia spp. in the United States, going back to at least 1883 (Farr and Rossman 2015). It is unknown how the current disease outbreaks on $R$. fulgida are related to the earlier reports of $P$. halstedii on wild perennial Rudbeckia species. There is no evidence to indicate that the epidemic strains of $P$. halstedii are able to infect any species other than cultivated rudbeckia, and there is some anecdotal information suggesting the contrary. In the nursery industry, at least 25 species of Rudbeckia are commonly grown, including wild native species such as $R$. subtomentosa and $R$. hirta. However, to our knowledge, there are no contemporary reports of RDM from any other species of Rudbeckia other than R. fulgida. Only R. fulgida has been affected in nurseries where RDM has been reported, even where other species (e.g., $R$. hirta) are grown in adjacent areas (Hong 2006; Rivera et al. 2015a).

In the present study, we address the question of whether modern RDM epidemics on cultivated rudbeckia are caused by the same $P$. halstedii genotype(s) as those associated with wild, North American native rudbeckia species that were collected prior to the epidemics. At the same time, we set out to determine the relationship between rudbeckia-infecting $P$. halstedii genotypes and those responsible for sunflower downy mildew disease. In both cases, the goal is to determine whether either of these resident $P$. halstedii genotypes could have served as the source population(s) for the recent RDM outbreaks. To address these questions, we employ a combined population genetic and phylogenetic approach to evaluate a worldwide collection of $P$. halstedii infecting species of sunflower and rudbeckia, from both modern and historical sources. Because few molecular resources are available to support these investigations at the population level, we generated a draft genome sequence from $P$. halstedii, and used it as the basis for development of a set of simple sequence repeat (SSR) markers. Together with phylogenetic reconstructions, these analyses allow us to determine the genetic variability of $P$. halstedii from two economically important host plants, and clarify the relationship between pre- and postepidemic pathogen populations on rudbeckia and sunflower.

\section{MATERIALS AND METHODS}

Plasmopara halstedii samples and DNA extraction. A collection of 232 P. halstedii from nine countries was analyzed (Table 1; Supplementary Table $\mathrm{S} 1$ ). We refer to $P$. halstedii samples collected between 1883 and 1999 as "historical" or pre-epidemic, while those collected between 2000 and 2014 were considered "modern", or postepidemic. These broad designations are based on the timing of disease outbreaks: (i) the emergence of new virulent $P$. halstedii races that overcame important sources of disease resistance in sunflower starting around 2000 (Gulya et al. 2010; Tourvieille et al. 2000); and (ii) RDM outbreaks on rudbeckia that began in 2004. Historical samples from $H$. annuus were collected between 1984 and 1999. These samples were maintained as sporangial collections stored under liquid nitrogen at the USDA-ARS facility in Fargo, ND as described (Gulya et al. 1993). Historical samples of $P$. halstedii on the native plant species H. strumosus, R. triloba, $R$. laciniata, and Rudbeckia sp. were obtained from the U.S. National Fungus Collection in Beltsville, MD (herbarium BPI). The
BPI samples were originally collected between 1883 and 1936, and were maintained in acid-free paper envelopes at room temperature $\left(24^{\circ} \mathrm{C}\right)$ as dried, pressed plant material colonized by $P$. halstedii. Ninety-four modern samples were collected between 2000 and 2014 from $R$. fulgida 'Goldsturm' ( $n=59)$, R. fulgida var. speciosa $(n=1)$, and $H$. annuus $(n=24)$ from nurseries and landscapes across the United States and one from France (sample SDM128).

Dried sporangial masses were removed from infected leaf tissue by vacuum or by scraping the leaf surface with a sterile needle. Approximately $100 \mathrm{mg}$ of sporangial tissue was homogenized using $100 \mathrm{mg}$ of $0.5 \mathrm{~mm}$ glass beads (Scientific Industries Inc., Bohemia, NY) in a FastPrep-24 homogenizer (MP Biomedicals, Solon, OH). Total genomic DNA was extracted using a modified OmniPrep DNA Extraction protocol (G-Biosciences, St. Louis, MO). Briefly, larger quantities of lysis buffer $(600 \mu \mathrm{l})$, DNA stripping solution $(60 \mu \mathrm{l})$, precipitation solution $(150 \mu \mathrm{l})$, and $70 \%$ ethanol $(1 \mathrm{ml})$ were used. For samples with few sporangia, approximately $0.5 \mathrm{~cm}$ sections of visibly infected leaf tissue were ground using a mortar and pestle with liquid nitrogen, and genomic DNA was extracted following the DNeasy Plant Mini Kit protocol (Qiagen, Germantown, MD).

Genome sequencing and de novo assembly. Whole genome sequencing was performed from $P$. halstedii sample SDM74, collected in 2009 from $H$. annuus in Bottineau, ND. This sample was selected for whole genome sequencing based on the economic importance of the physiological race it represents. Sample SDM74 is classified as a member of physiological race 734, one of the first 'hot' races virulent against the $P l_{6}$ and $P l_{7}$ resistance genes in commercial sunflowers (Gulya et al. 2010). Sequencing libraries were created from genomic DNA using Illumina's Nextera XT and Nextera Mate-Pair kits and sequenced using Illumina's MiSeq sequencing-by-synthesis technology with 300-bp paired-end reads (Illumina, Inc., San Diego, CA). Fastq read files were imported into CLC Genomics Workbench v.7.5.1 (CLC Bio, Boston, MA) where Illumina adapters and indices, low quality reads and ambiguous bases were removed. De novo assembly of trimmed/filtered reads was performed using an empirically determined k-mer size of 40, bubble size of 100 , with contigs $\geq 500$ bp retained.

Additional Illumina DNA sequence reads were generated from two $P$. halstedii samples from sunflower and four samples from rudbeckia ( $R$. fulgida 'Goldsturm') to provide a shallow depth of coverage suitable for comparison with the SMD74 reference assembly (Supplementary Table S2). Sequencing libraries for these six samples were constructed using Nextera XT, TruSeq, and TruSeq Nano kits and sequenced on an Illumina MiSeq to generate 300-bp paired-end reads.

SSR identification and primer design. The genome assembly of $P$. halstedii SDM74 was used for genome-wide identification of SSR motifs (MISA) (Thiel et al. 2003), primer design (Primer3; Untergasser et al. 2012) and a reciprocal BLAST search to identify multiple priming sites within the genome (Altschul et al. 1990). The analysis was completed using the automated pipeline implemented in PrimerPro v1.0 (http://webdocs.cs.ualberta.ca/ yifeng/primerpro/). Search parameters were performed as previously described (SalgadoSalazar et al. 2015). Using CLC Genomics Workbench, SSR motifs and Illumina sequence reads from the four $P$. halstedii samples (SDM74, RDM1, RDM4, RDM5) were mapped to the SDM74 reference assembly. Candidate SSR markers were preferentially selected by identifying SSR regions represented by sequence reads in at least one $P$. halstedii samples from each host. Because genome sequencing

TABLE 1. Summary of Plasmopara halstedii samples genotyped using simple sequence repeat markers designed in this study

\begin{tabular}{lcccc}
\hline & $\begin{array}{c}\text { Historical } \\
(1883-1999)\end{array}$ & $\begin{array}{c}\text { Modern } \\
(2000-2014)\end{array}$ & $\begin{array}{c}\text { Unknown } \\
\text { (data not available) }\end{array}$ & Total \\
\hline Helianthus spp. & 115 & 24 & 28 & 167 \\
Rudbeckia spp. & 5 & 60 & - & 65 \\
Total & & & & 232 \\
\hline
\end{tabular}


was performed directly from environmental samples, the contigs selected for SSR primer design were queried against the NCBI GenBank nucleotide database to ensure that they originated from P. halstedii.

De novo gene predictions on the regions containing target SSR motifs were conducted using the AUGUSTUS web interface (http:// bioinf.uni-greifswald.de/webaugustus/prediction/create) with gene model parameters trained for Saccharomyces cerevisiae. BLASTp and BLASTn searches of the NCBI GenBank nonredundant database were used to provide putative identifications of the predicted proteins and noncoding regions, respectively.

SSR genotyping. Amplifications were carried out following the approach of Schuelke (2000). PCR reactions were performed in a $10 \mu \mathrm{l}$ volume containing $2 \times$ Mango Mix, $12.5 \mathrm{mM}$ of $\mathrm{MgCl}_{2}$ (Bioline Inc., Tauton, MA), $2.5 \mu \mathrm{M}$ forward primer with a 5' M13 tail, $5 \mu \mathrm{M}$ reverse primer, and $5 \mu \mathrm{M}$ M13 primer labeled with one of the following fluorophores: 6FAM (Integrated DNA Technologies, Coralville, IA), VIC, NED or PET (Applied Biosystems, Foster City, CA). Each reaction contained $1.5 \mu \mathrm{l}$ of genomic DNA (final concentration: 10 to $100 \mathrm{ng} / \mu \mathrm{l})$. Reactions were carried out in a thermal cycler (C100 Thermal Cycler, Bio-Rad Laboratories, Hercules, CA or PTC-100 Gradient Cycler, MJ Research, Watertown, MA) under the following conditions: initial denaturation at $94^{\circ} \mathrm{C}$ for $5 \mathrm{~min} ; 30$ cycles at $94^{\circ} \mathrm{C}$ for $30 \mathrm{~s}, 57^{\circ} \mathrm{C}$ annealing temperature for $45 \mathrm{~s}$, and $72^{\circ} \mathrm{C}$ for $45 \mathrm{~s}$; a labeling step of 8 cycles at $94^{\circ} \mathrm{C}$ for $30 \mathrm{~s}, 53^{\circ} \mathrm{C}$ for $45 \mathrm{~s}$, and $72^{\circ} \mathrm{C}$ for $45 \mathrm{~s}$; and a final extension step at $72^{\circ} \mathrm{C}$ for $10 \mathrm{~min}$. All PCR reactions included a minimum of two negative controls consisting of water or DNA extracted from healthy sunflower leaf tissue. A subset of the PCR amplifications including negative controls were visually confirmed on a $2 \%$ agarose gel. Samples with no PCR amplification for a given marker were repeated once. PCR amplicons were prepared for fragment analysis by mixing $1 \mu \mathrm{l}$ of undiluted PCR product and $9 \mu \mathrm{l}$ of loading buffer $(9 \mu \mathrm{l}$ of HiDi formamide [Applied Biosystems] and $0.2 \mu \mathrm{l}$ of GeneScan 500 LIZ size standard [Applied Biosystems]). SSR reactions were multiplexed in groups of four, by combining SSR markers labeled with one of each of the four fluorescent labels. Fragment analysis was performed on a $3730 \times 1$ DNA Analyzer (Applied Biosystems). Results were scored using GeneMarker v2.6.3 (SoftGenetics, State College, PA). Five percent of reactions were duplicated to confirm allele calls.

Population analysis. GenAlEx v.6.5 (Peakall and Smouse 2012) was used to calculate the number of unique multilocus genotypes, total number of alleles per locus, unbiased gene diversity $(h)$, and Shannon's information index. A genotype accumulation curve was calculated using the statistical language $\mathrm{R}$ (R Core team 2015) and the package poppr (Kamvar et al. 2014) to determine the efficiency of the SSR markers in discriminating unique multilocus genotypes in our data set. Population clusters were defined using the Bayesian clustering algorithm implemented in STRUCTURE 2.3.4 without a priori definitions (Falush et al. 2007, 2003; Hubisz et al. 2009; Pritchard et al. 2000), using a burn-in period of 500,000 and 500,000 Monte Carlo Markov Chain (MCMC) iterations for data collection and 10 independent simulations for each K (1 to 25). Admixture and correlated allele frequencies models were evaluated for every K. A second analysis in STRUCTURE was performed for each of the previously identified clusters using the same parameters and evaluating Ks from 1 to 10 . The optimal $\mathrm{K}$ value was chosen by comparing the rate of change in the log probability of the data between $\mathrm{K}$ values (DeltaK) using the web-based program STRUCTURE HARVESTER (Earl and vonHoldt 2012; Evanno et al. 2005). Clusters were visualized using the default settings for CLUMPP and DISTRUCT in the beta version of the web-based pipeline Cluster Markov Packager Across K (CLUMPAK; Kopelman et al. 2015). A principal coordinate analysis (PCA) using pairwise genotypic distance between all samples was calculated with GenAlEx v.6.5 to visualize additional genetic variation patterns within and between clusters.
Multilocus sequencing and phylogenetic analysis. Seven sunflower downy mildew (SDM) and RDM samples were analyzed for phylogenetic relationships using sequence data generated from the cytochrome oxidase subunit II (cox2) and the rDNA internal transcribed spacer (ITS) regions. Local BLAST searches in CLC Genomics Workbench were used to identify and extract these sequences from the seven $P$. halstedii genome data sets. Four additional SDM samples were also included in the phylogenetic analysis of $\operatorname{cox} 2$. For these samples, genomic DNA was extracted from sporangial masses and infected leaf tissue as described above. PCR amplifications were performed using the primer pair Cox $2-\mathrm{F} /$ Cox2-RC4 ( $\operatorname{cox} 2$; Choi et al. 2015; Hudspeth et al. 2000), and the primer pair ITS1-O/LR-O (ITS; Moncalvo et al. 1995; Spring et al. 2006). PCR conditions were as follows: (i) $\operatorname{cox} 2: 95^{\circ} \mathrm{C}$ for $4 \mathrm{~min}$ followed by 36 cycles at $95^{\circ} \mathrm{C}$ for $40 \mathrm{~s}, 55^{\circ} \mathrm{C}$ for $40 \mathrm{~s}$ and $72^{\circ} \mathrm{C}$ for $60 \mathrm{~s} ; 5 \mathrm{~min}$ at $72^{\circ} \mathrm{C}$; (ii) ITS: $94^{\circ} \mathrm{C}$ for $3 \mathrm{~min}$ followed by $94^{\circ} \mathrm{C}$ for $30 \mathrm{~s}, 47^{\circ} \mathrm{C}$ for $30 \mathrm{~s}, 72^{\circ} \mathrm{C}$ for $1 \mathrm{~min} ; 72^{\circ} \mathrm{C}$ for $10 \mathrm{~min}$. All amplified fragments were confirmed on a $1 \%$ agarose electrophoresis gel. After removal of unused primers and nucleotides using Illustra ExoStar (GE Healthcare Life Sciences, Piscataway, NJ), PCR products were sequenced bidirectionally using BigDye Terminator v3.1 cycle sequencing chemistry (Applied Biosystems) on an ABI 3730x Genetic Analyzer (Applied Biosystems). Sequences were assembled and edited to remove low quality bases using CLC Genomics Workbench and consensus sequences were extracted for phylogenetic analysis.

Data sets for each sequence marker were aligned separately using CLC Genomics Workbench. The best fitting substitution model for each marker was determined using the software jModeltest (Darriba et al. 2012; Guindon and Gascuel 2003) and models were chosen according to the Akaike information criterion (Akaike 1974). The models TIM2+I+G and TVM+I were chosen as the best fit for the cox2 and ITS data sets, respectively. Phylogenetic relationships were reconstructed using maximum likelihood optimality criterion implemented in the RAxML-GUI (Silvestro and Michalak 2012; Stamatakis 2006), with 1,000 nonparametric bootstrap replicates performed to assess branch support. Peronospora belbahrii was used as outgroup taxa to root the phylogenetic trees, consistent with the known phylogenetic relationship between the Plasmopara and Peronospora genera (Thines et al. 2008). Final trees were visualized with FigTree v1.3.1 (Rambaut 2009). DNA sequences generated in this study were deposited in GenBank (Tables 3 and 4). Voucher specimens of $P$. halstedii were submitted to herbarium BPI under accessions 909964 to 910041.

Cross-infectivity experiments. A $P$. halstedii sample from R. fulgida 'Goldsturm' collected from a commercial greenhouse in Maryland during 2013 (RDM5) was used to test for cross infectivity on $H$. annuus according to the protocol published by Gulya (1996). Zoosporangia rinsed from $R$. fulgida 'Goldsturm' leaves were used to inoculate 3 -day-old $H$. annuus seedlings. Seedlings were immersed in a zoosporangial suspension of 20,000 sporangia/ml for $3 \mathrm{~h}$, and planted in a sand-perlite mixture $(3: 1, \mathrm{vol} / \mathrm{vol})$ in the greenhouse for 11 to 12 days under the following conditions: 18 to $24^{\circ} \mathrm{C}, 16 \mathrm{~h}$ photoperiod. Zoosporangia from the same sample were also used to inoculate a series of nine sunflower differential lines to determine the physiological race of this sample (Gulya et al. 1991).

\section{RESULTS}

Development and characteristics of new SSR markers. Five hundred fifty-nine scaffolds were assembled into a draft genome sequence for $P$. halstedii sample SDM74. Seventy percent of the Illumina sequence reads generated for RDM4 (9.4 M) and RDM5 (17.4 M) mapped to the SDM74 scaffolds, but only $54 \%$ of the Illumina reads generated for sample RDM1 (2.7 M) could be mapped to the SDM74 scaffolds. A total of 682 SSR-containing regions were identified from the 559 SDM74 scaffolds (Table 2). The predominant motifs were di-nucleotide repeats $(n=322)$, 
followed by tri- and penta- nucleotide repeats $(n=152$ and 112 , respectively). From the genome assembly and mapping file data sets, 38 SSR-containing regions were selected for primer design and evaluated for amplification and polymorphism using a set of 14 $P$. halstedii samples from two different hosts, $H$. annuus and R. fulgida 'Goldsturm'. From the 38 primer pairs evaluated, seven primer pairs only amplified $P$. halstedii collected from $H$. annuus, five primer pairs were monomorphic, and seven primer pairs exhibited inconsistent amplification (data not shown). The remaining 19 polymorphic SSR primer pairs were initially used to genotype a set of $547 P$. halstedii samples that included herbarium specimens from multiple hosts within the family Asteraceae (collected from 1883 to 1930s; data not shown). However, the herbarium specimens from hosts other than Helianthus and Rudbeckia did not amplify consistently and were removed from the study (data not shown), leaving 232 samples. After genotyping the remaining 232 P. halstedii samples, four additional SSR markers were removed from the final analysis due to inconsistent allele calls. A summary of the final 15 SSR markers selected for genotypic analyses is provided in Table 3. These markers were distributed across 15 different scaffolds of the $P$. halstedii SDM74 genome assembly, with 10 of the 15 markers predicted to fall within genic regions. Ten SSR markers exhibited high levels of similarity to hypothetical proteins of Phytophthora parasitica and Phytophthora infestans, and one marker was similar to a genomic DNA sequence from Hyaloperonospora parasitica. No significant hits were obtained from BLASTn searches performed using the remaining four SSR markers in nongenic regions (Table 3 ).

PCR reactions using the 15 SSR markers yielded amplicons ranging in size from 133 to $301 \mathrm{bp}$, with 4 to 12 alleles per locus. Unbiased gene diversity ranged from 0.34 to 0.68 and the Shannon's information index ranged from 0.61 to 1.77 . The genotype accumulation curve showed that nine loci were sufficient to discriminate $90 \%$ of the multilocus genotypes in our data set (Supplementary Fig. S1). Failed PCR amplifications were more common within the RDM samples than SDM. The highest percentages of missing data resulted from markers $2118(17 \%), 354(17 \%)$ and $4499(16 \%)$. Marker 2118 failed to amplify all SDM and RDM herbarium samples equally, while marker 4499 failed to amplify a large percentage of RDM samples (38\%). Missing data for all other loci ranged between 3 and $14 \%$.

Population genetic structure. From 232 P. halstedii samples, 231 exhibited unique multilocus genotypes. Only two samples collected from the same location shared a unique multilocus genotype at 14 loci (RDM30 and RDM33). The genotypic diversity in our data set was also reflected by a large number of private alleles (i.e., alleles unique to a population). When the data set was subdivided by plant host genus, 14 alleles at eight loci were unique to the RDM samples (allele frequencies range from 0.008 to 0.67 ), while 34 alleles at 13 loci were unique to the SDM samples (allele frequencies range from 0.003 to 0.46 ). Five private alleles at four loci were also observed across all herbarium samples of RDM collected from 1883 to 1936 (allele frequencies range from 0.125 to 0.8 ).

When all $232 P$. halstedii samples were analyzed using STRUCTURE, the deltaK was maximized when $\mathrm{K}=2$ (DeltaK = 4,280.8; Supplementary Fig. S2). These two sample clusters divided the $232 P$. halstedii samples entirely according to host plant origin, with one cluster exclusive to Helianthus spp. (designated cluster A) and one cluster exclusive to Rudbeckia spp. (designated cluster B; Fig. 1A), with almost no admixture. Clustering by plant host was also observed in the PCA (Fig. 2), where $30 \%$ of the variance was explained by the first two coordinates. As with the STRUCTURE analysis, sample characteristics such as year of collection, country of origin, or physiological race did not explain secondary clustering of samples within the PCA. Interestingly, historical pre-epidemic samples collected from Rudbeckia spp. between 1883 and 1936 loosely clustered between the two main plant host clusters for P. halstedii (Fig. 2). To explore if this was an artifact of the missing data found in the historical RDM samples, we calculated a PCA using a reduced number of loci. After discarding loci with over $60 \%$ missing data (loci 147, 354, 1213, 2010, 2118, and 5056) in historical RDM samples, the PCA analysis yielded similar results as observed in the complete PCA (data not shown).

STRUCTURE analysis performed using only SDM samples in cluster A identified eight clusters (designated subclusters A1 to A8; $\mathrm{K}=8$, DeltaK = 11.5; Supplementary Fig. S3; Supplementary Table $\mathrm{S} 3$ ). None of the eight SDM subclusters A1 to A8 corresponded with country of origin, year of collection, or physiological races (Fig. 1B). All SDM subclusters included samples collected over a time period of at least 11 years (A3), and up to 102 years (A7). The sole SDM herbarium specimen-collected in the year 1911 from H. strumosus (BPI 796453) — was placed in cluster A7, along with samples collected between 1990 and 2013. Physiological race groups were distributed across different SDM subclusters. For example, 15 samples of $P$. halstedii race 700 clustered in six different SDM subclusters (A1, A2, A4, A5, A7, and A8), while the 33 samples of race 730 were found in all eight SDM subclusters. Admixture between SDM subclusters occurred throughout the sample (Fig. 1B).

Within P. halstedii cluster B from Rudbeckia spp., STRUCTURE analysis subdivided samples into three main subclusters $(\mathrm{K}=3$, DeltaK = 82.0; Supplementary Fig. S4; Supplementary Table S4). Subcluster B1 contained the five historical $P$. halstedii samples collected on native Rudbeckia hosts from 1883 to 1936 (Fig. 1C). There was no evidence of admixture between historical subcluster B1 and the modern RDM samples in subclusters B2 and B3. Subcluster B2 consisted of 20 modern RDM samples collected from two commercial nurseries in Maryland, and landscape samples from Connecticut, Tennessee, Virginia, Ohio and Maryland during 2013 and 2014. All but two samples in subcluster B2-from a single nursery in Maryland-were collected during 2013. Subcluster B3 contained 40 RDM samples collected during 2013 and 2014 from three commercial nurseries in Maryland and from a nursery-grown sample of $R$. fulgida var. speciosa from Indiana. Samples collected from one commercial nursery in 2013 originated from three different supplier shipments during, April, July and August (Fig. 1C). Clustering analysis in STRUCTURE showed that $P$. halstedii genotypes from the April shipment belonged entirely to subcluster B2. In contrast, RDM samples collected from the July cluster belonged to both B2 and B3 subclusters, while the August RDM sample group from the same nursery belonged almost entirely to subcluster B3 (except one sample). Ninety-three percent of the samples collected in 2014 belonged to subcluster B3, and originated from two local commercial nurseries (Fig. 1C).

Phylogenetic analysis. Eleven cox 2 and seven ITS rDNA sequences were obtained from RDM and SDM samples (Table 4). As observed from the SSR data sets, phylogenetic analyses of these data sets revealed a separation of the SDM and RDM $P$. halstedii samples into two distinct clades that corresponded with plant host genus. Although the distinction between clades of $P$. halstedii from

TABLE 2. Summary statistics from Plasmopara halstedii sample SDM74 draft genome assembly

Statistics

Draft genome statistics

Draft genome assembly size

Number of scaffolds $\geq 500 \mathrm{bp}$

N50

Average scaffold length

Average coverage

Simple sequence repeat (SSR) statistics

Number of scaffolds examined

Number of scaffolds with SSRs

Number of identified SSRs
$70 \mathrm{Mb}$

8,385

25,074

8,352

$192 \times$

8,385

559 
SDM and RDM was also observed in cox2 and ITS rDNA phylogenetic trees, only the RDM samples showed high bootstrap values within both phylogenies (99\%; Fig. 3). Samples from SDM clustered together with high bootstrap support only in the ITS phylogeny (97\%; Fig. 3B). Despite the low branch support, phylogenetic analysis of cox 2 further divided SDM samples into two distinct clades (Fig. 3A).

Cross-infectivity between different host genera. Signs and symptoms characteristic of downy mildew disease, using sporangia originally collected from R. fulgida 'Goldsturm' (sample RDM5), were observed on sunflower seedlings 12 days after inoculation. Profuse sporulation was observed on cotyledons and the first pair of true leaves in 98 to $100 \%$ of all inoculated seedlings. Evaluation of this same sample on nine sunflower differential lines identified it as a member of $P$. halstedii race 734 .

\section{DISCUSSION}

In this study, we developed new molecular resources and used them to determine whether recent outbreaks of downy mildew on rudbeckia in the United States are caused by the same $P$. halstedii genotypes responsible for pre-epidemic disease outbreaks on native Rudbeckia sp., or disease outbreaks on cultivated sunflower. Through the analysis of 60 modern RDM samples and five historical RDM herbarium specimens using SSRs and two phylogenetic sequence markers, we observed unique genotypes that served to delineate preand postepidemic pathogen populations from each other, and from SDM samples. In particular, these data show that $P$. halstedii causing the modern RDM epidemics on cultivated $R$. fulgida are genetically different from the $P$. halstedii samples associated with historical disease outbreaks on native Rudbeckia spp. Modern RDM samples characterized in this study exhibit high genetic diversity and a lack of genetic structure, even when one considers the small geographical region and two year time frame used for sample collection. For example, the $R$. fulgida plants from which RDM samples were collected in 2013 at one nursery were received from wholesale suppliers at three different times: April, July and August. Interestingly, genetic changes in the pathogen populations can be observed between the shipments received in April (belonging exclusively to subcluster B2) and August (subcluster B3), with a genetically mixed

TABLE 3. Characteristics of the 15 polymorphic simple sequence repeat markers developed for Plasmopara halstedii in this study ${ }^{\mathrm{a}}$

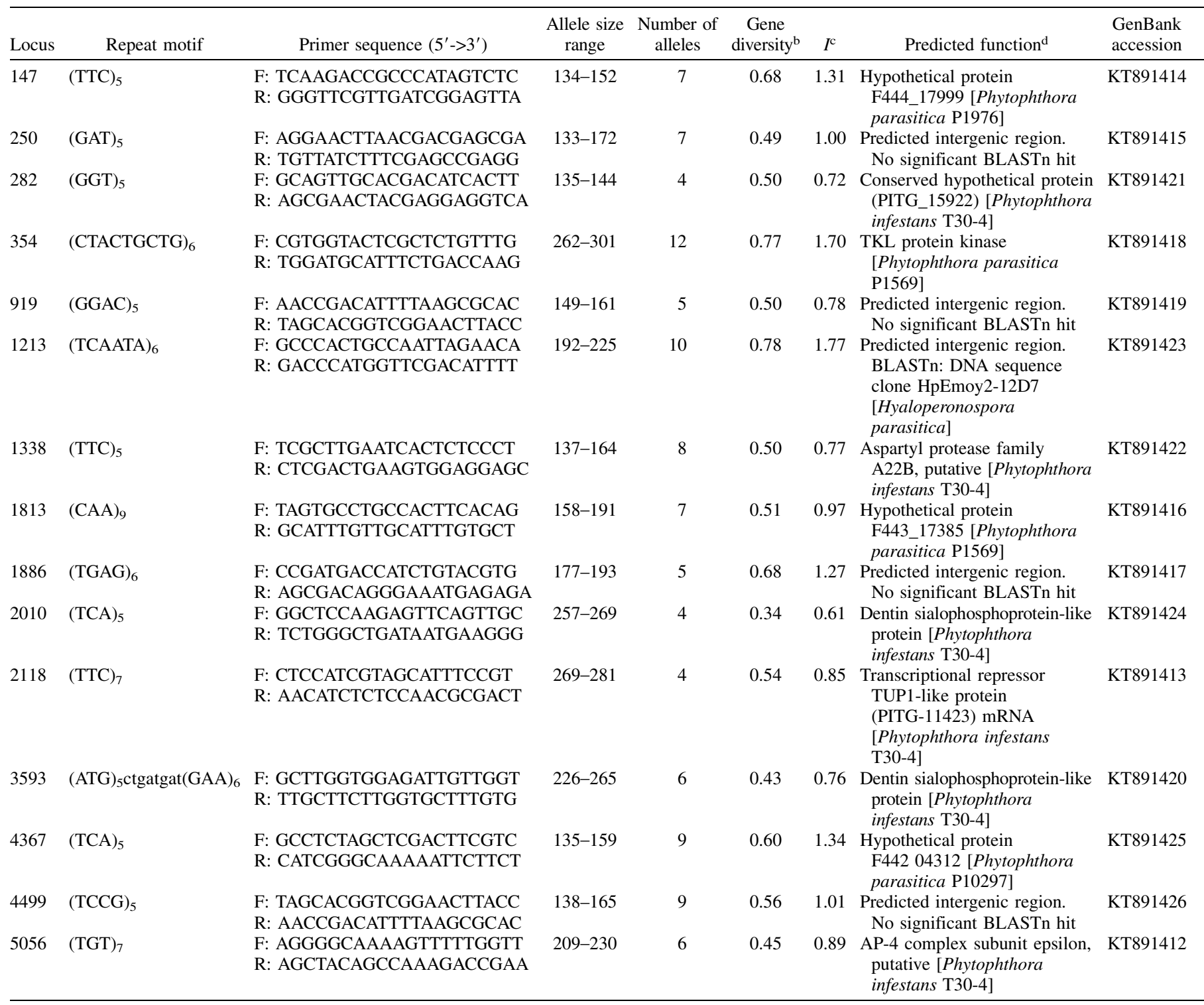

${ }^{a}$ Fluorophores were added to forward primers as described in Schuelke 2000.

b Gene diversity (unbiased heterozygosity $\left[2 n / 2 n-1\left(1-\Sigma p_{i}{ }^{2}\right]\right.$ ) was calculated using GenAlEx v.6.5 (Peakall and Smouse 2012).

c $I=$ Shannon's information index, $-1 \times \Sigma\left(p_{i} \times \operatorname{Ln}\left(p_{i}\right)\right)$, was calculated using GenAlEx v.6.5 (Peakall and Smouse 2012).

d Predicted genic regions are based on results from AUGUSTUS web interface and BLAST queries of the NCBI nonredundant database. 
sample group collected in July (subclusters B2 and B3; Fig. 1C). The predominant genetic subcluster (B3) identified at the end of the 2013 growing season at this nursery was also the predominant subcluster sampled in 2014 at all sites. Although this pattern may have been influenced by the localized nature of our sampling, our data highlight the striking presence of multiple genetic groups within a single growing season and within a single commercial operation. Oomycete plant pathogens are known to evolve rapidly and overcome strategies for disease management in a very short time (Ahmed et al. 2012; Callaghan and Guest 2015; Gulya et al. 2013). The results of our study support the existence of high levels of genetic diversity in P. halstedii infecting Rudbeckia spp., and the potential for rapid evolution of its populations.

Analysis of 232 modern and historical samples identified the existence of two well-defined clusters using SSR markers and molecular phylogenetic trees. The differentiation between RDM and SDM samples is consistent with a species-level diversification, based on the reciprocal monophyly in phylogenetic analyses and multilocus genotype clustering. The two main clusters corresponded, unequivocally, to the two plant host genera examined in our study, regardless of the type of marker employed. The SSR markers developed in our study revealed a high level of genetic diversity (up to 12 alleles/locus) and discriminative power between samples of these two putative Plasmopara species. Furthermore, the lack of transferability of these SSR markers among P. halstedii isolates collected from different Asteraceae hosts indicates that these markers are highly specific to the two host isolate groups. This observation suggests the existence of multiple divergent species associated with other Asteraceae hosts, such as Bidens spp., Eupatorium spp. and Erigeron spp. Our finding is in agreement with the narrow species concept proposed for $P$. halstedii by Novotel'nova (reviewed by Choi et al. 2009) based on morphometric characters, and with more recent molecular work (Komjáti et al. 2007; Spring et al. 2006, 2003; Voglmayr et al. 2004). Molecular and morphological work by Choi et al. (2009) revealed that the downy mildew on Ambrosia artemisifolia (common ragweed) is also caused by a Plasmopara sp. different from the previously reported $P$. halstedii and $P$. angustiterminalis. Similarly, $P$. sphagneticolae (on Sphagneticola; McTaggart et al. 2015) and P. majewskii (on Arctotis and Arctotheca; Constantinescu and Thines 2010) are newly described species, morphologically and genetically distinct from $P$. halstedii infecting different hosts within the family Asteraceae. As suggested previously by Thines (2014) and supported by our results, $P$. halstedii sensu lato is a complex of species that warrants an in-depth taxonomic revision to elucidate the limits of its host range. A taxonomic reclassification of the Plasmopara species causing downy mildew disease on rudbeckia and sunflower, while necessary, is outside the scope of our study, and thus needs to be comprehensively addressed in future research.

Despite the clear genetic distinction between $P$. halstedii samples originating from Rudbeckia spp. and Helianthus spp., our pathogenicity assay determined that cross infection from a $P$. halstedii isolate from rudbeckia onto sunflower seedlings is still possible under controlled conditions. Few studies have reported on the pathogenicity of $P$. halstedii sensu lato between different host genera relative to its wide host range. To our knowledge, demonstration of cross infectivity between $P$. halstedii isolates from other Asteraceae genera and sunflower is limited to just five genera: Ambrosia, Dimorphotheca, Iva, Rudbeckia, and Xanthium (Gulya 2002; Leppik 1965; Viranyi 1984; Walcz et al. 2000; and this study). This phenomenon, if common in nature, could provide a large suite of plants acting as reservoirs for $P$. halstedii to infect economically important crops. However, similar pathogenicity assays in the field are lacking and molecular studies consistently suggest that field isolates collected on different host genera are genetically distinct (Choi et al. 2009; Komjáti et al. 2007). In our study, the same isolate used for the cross infectivity assay (RDM5) was found to be genetically distinct from isolates on Helianthus sp. using SSR and phylogenetic analysis. While we did not inoculate rudbeckia with $P$. halstedii isolates from sunflower host, previous attempts indicate that systemic infection on rudbeckia seedlings is not possible (T. J. Gulya, unpublished data). Together, these data suggest that although cross-infectivity is possible under controlled conditions, movement of different $P$. halstedii genotypes between different Asteraceae hosts may be rare or nonexistent in natural populations under ordinary conditions.

The collection of $P$. halstedii isolates from cultivated sunflower included in this study encompasses 14 different physiological races

TABLE 4. Collection information on the Plasmopara samples used for phylogenetic analyses

\begin{tabular}{|c|c|c|c|c|}
\hline Species & Host & Sample ID & $\begin{array}{c}\text { ITS GenBank } \\
\text { accession number }\end{array}$ & $\begin{array}{c}\text { cox2 GenBank } \\
\text { accession number }\end{array}$ \\
\hline \multirow{10}{*}{ Plasmopara halstedii } & Helianthus annuus & SDM1 & - & KU232275 \\
\hline & H. апnиus & SDM33 & KU232270 & KU232280 \\
\hline & H. аппииз & SDM142 & - & KU232276 \\
\hline & H. аппииs & SDM146 & - & KU232277 \\
\hline & H. аппииs & SDM147 & - & KU232278 \\
\hline & H. аппииs & SDMR710 & KU232274 & KU232285 \\
\hline & Rudbeckia fulgida 'Goldsturm' & RDM1 & KU232272 & KU232282 \\
\hline & R. fulgida 'Goldsturm' & RDM4 & - & KU232283 \\
\hline & R. fulgida 'Goldsturm' & RDM5 & KU232273 & KU232284 \\
\hline & R. fulgida 'Goldsturm' & RDM37 & KU232271 & KU232281 \\
\hline P. angustiterminalis & Xanthium strumarium & Pa676 & DQ993167 & - \\
\hline P. angustiterminalis & Xanthium sp. & MT X03A1 & - & EU826097 \\
\hline P. baudysii & Berula erecta & HV 571 & - & EU826098 \\
\hline P. siegesbeckiae & Siegesbeckia glabrescens & KUS-F 21312 & - & EU743814 \\
\hline P. sphagneticolae & Sphagneticola trilobata & BRIP 61010 & - & KM085175 \\
\hline P. viticola & Unknown & - & AY742739 & - \\
\hline P. viticola & Unknown & UASWS SG1 & - & EF426553 \\
\hline Peronospora belbahrii (outgroup) & Plectranthus scutellarioides & BPI893222 & KT828759 & - \\
\hline Peronospora belbahrii (outgroup) & Ocimum basilicum & HV2280 & - & EU863410 \\
\hline
\end{tabular}


collected from nine countries between 1984 and 2013. This allowed us to explore the potential for intraspecific (i.e., intra- and interrace) genetic patterns. The eight SDM subclusters identified in our study do not correspond to country of origin, year of collection, or physiological races. There is large variation in the characteristics of the samples within each subcluster. Most of the subclusters have a sample collection time range of 15 to 28 years, and all subclusters contain samples collected worldwide. SDM subcluster A7 contains the only herbarium sample from the native perennial $H$. strumosus (collected in 1911), but also includes samples collected from sunflower over a 102 year span (1990 to 2013). Only SDM subcluster A6 exclusively contains samples collected prior to 2000 , however, there is no other unique pattern from race or country of origin. A lack of correspondence between known physiological races in $P$. halstedii and molecular data has also been reported using RAPD markers (Roeckel-Drevet et al. 2003) and ITS sequence data (Spring et al. 2006). Using 12 expressed sequence tag (EST)derived markers, Delmotte et al. (2008) was only able to identify three distinct genetic groups from the 14 races present in France. Even when using single nucleotide polymorphisms identified from putative CRN cytoplasmic effectors, intraracial polymorphisms were the most commonly observed (As-sadi et al. 2011). Despite numerous efforts, no study performed to date has successfully developed molecular markers capable of replicating physiological race typing data that is generated through the labor-intensive phenotypic experiments with sunflower differential lines. It is known that physiological races of $P$. halstedii evolve rapidly in response to selection pressures manifested by the deployment of resistant hybrid plants (Gulya et al. 2013), and it is possible that the molecular markers that have been used to date are simply not sufficiently variable, or that they are not specifically targeted to the portions of the genomes that are affected by selective pressures. In the present study we preferentially selected loci that would produce PCR amplification across two distinct genetic groups from both sunflower and rudbeckia. Thus, it is likely that these fixed regions of the genome are more conserved across species than rapidly evolving regions associated with pathogenicity such as effector genes. For example, 10 of the SSR markers regions used in our study were recognizable in the distantly related oomycetes Phytophthora infestans, Phytophthora parasitica, and $H$. arabidopsis.

Parasexual recombination has also been previously suggested as an explanation for the appearance of new $P$. halstedii pathotypes (Delmotte et al. 2006; Spring et al. 2006), however, most investigators regard $P$. halstedii as an organism with a sexual stage in its lifecycle (reviewed in Gascuel et al. 2015). Either sexual or asexual recombination events could provide an explanation for the large number of unique multilocus genotypes in the $P$. halstedii sensu lato samples from sunflower. Recombination processes could also be responsible for the genetic clustering patterns observed in RDM from a single commercial nursery (commercial nursery 1) and
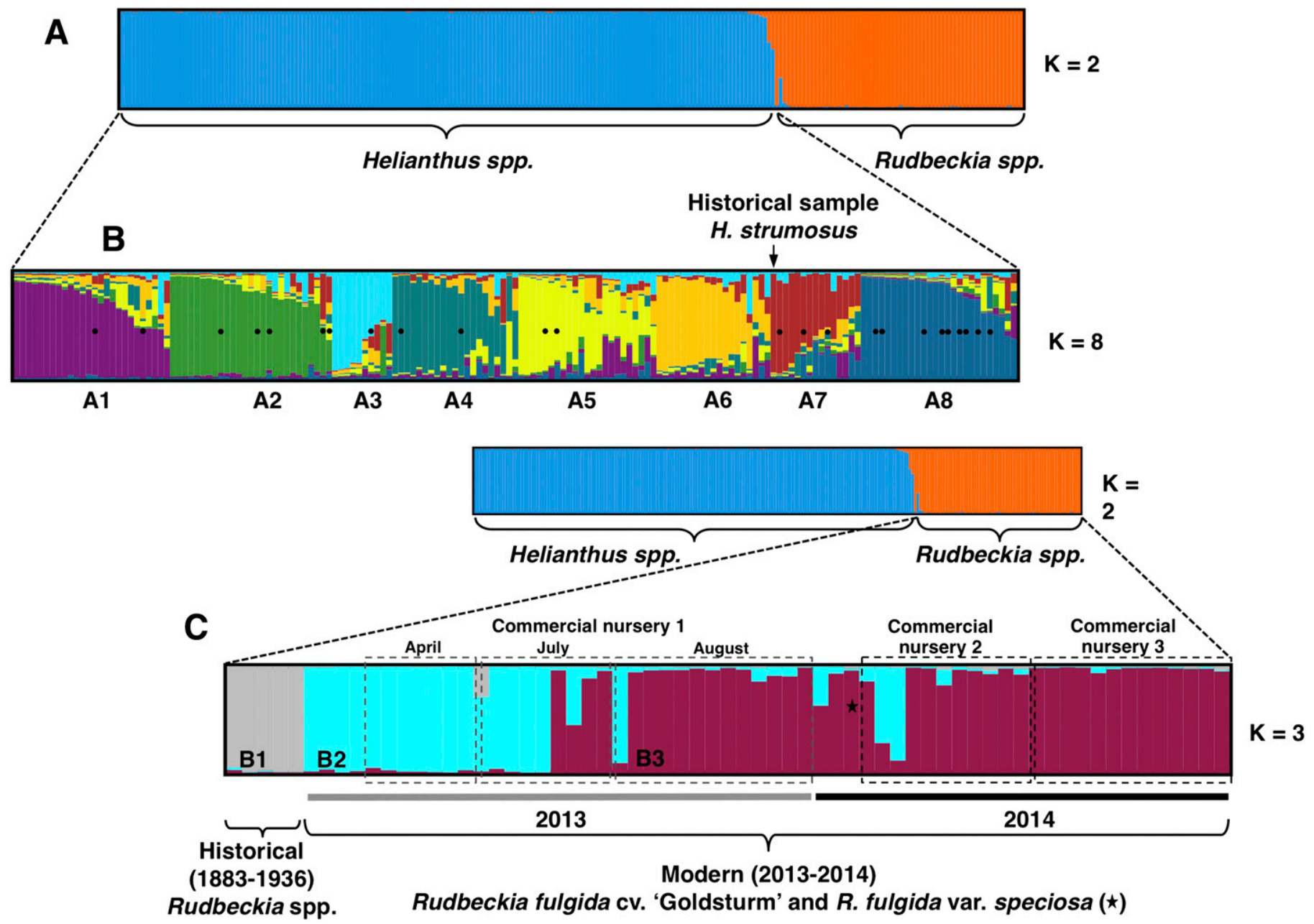

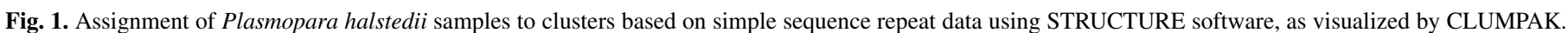

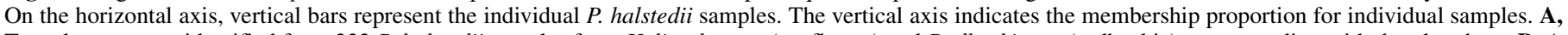

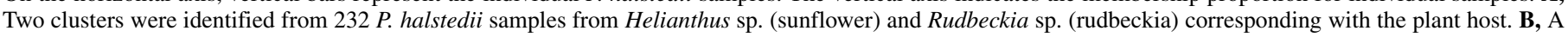

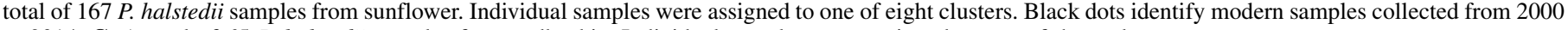
to 2014. C, A total of 65 P. halstedii samples from rudbeckia. Individual samples were assigned to one of three clusters. 
between years (Fig. 1C). These rapid microevolutionary changes in $\mathrm{RDM}$ and SDM populations may pose new challenges to disease prevention, management and control.

Historical samples allow scientists to take snapshots of organismal diversity from the past and compare it with the present (Choi and Thines 2015; Rossman 1996; Verkley et al. 2015; Yoshida et al.
2013). In the current study, historical specimens collected from native Rudbeckia spp. possess intermediate SSR genotypes, positioned between the cluster of modern RDM samples from cultivated R. fulgida and the cluster populated by SDM samples. Plasmopara halstedii and many of its Asteraceae hosts are considered native to North America, thus, populations of P. halstedii sensu

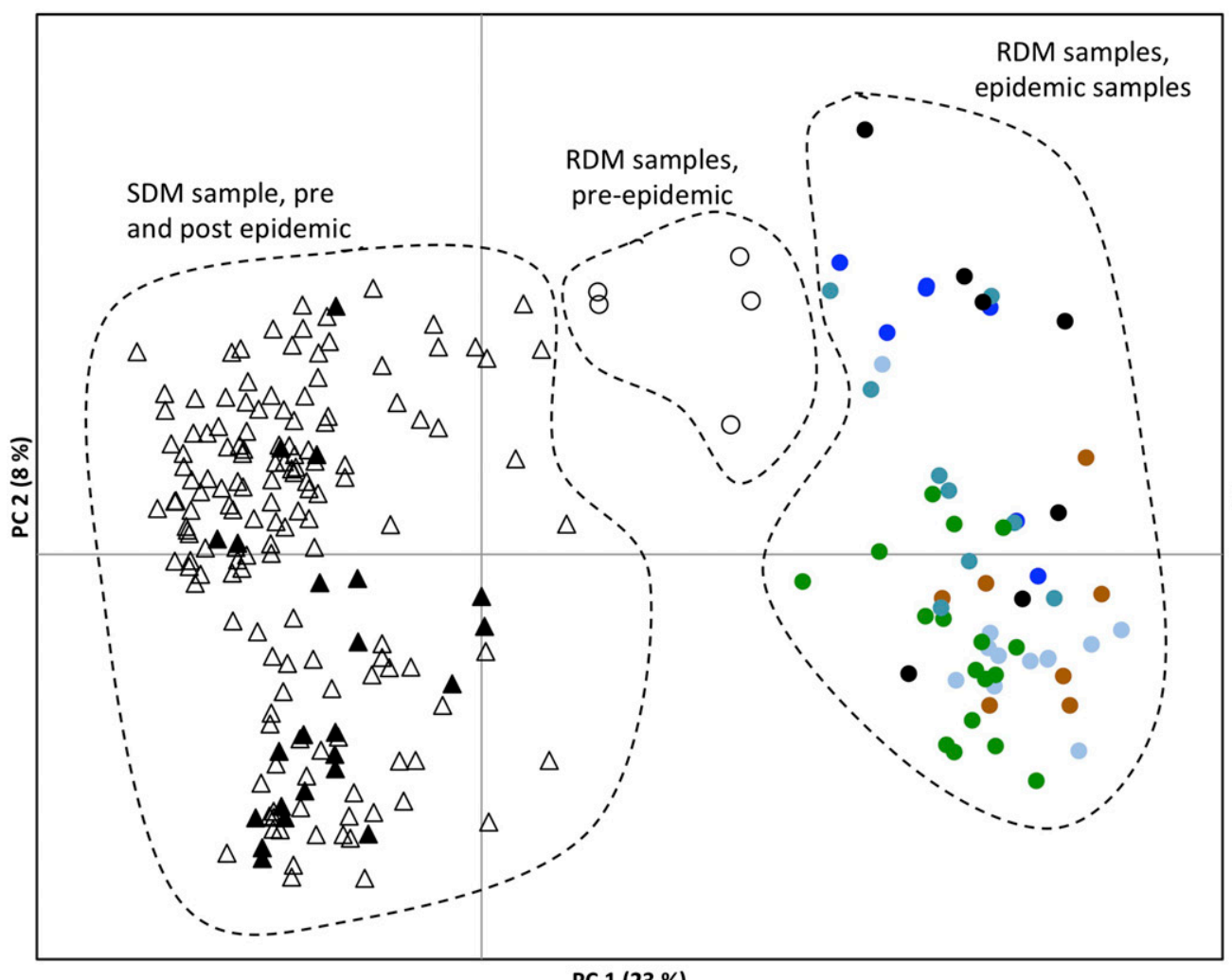

Figure key:

- RDM_Modern

- RDM_Commercial nursery 1 (April)

- RDM_Commercial nursery 1 (July)

- RDM_Commercial nursery 1 (August)

- RDM_Commercial nursery 2

- RDM_Commercial nursery 3

O RDM_Historical (1883 - 1936)

$\Delta$ SDM_Modern

$\triangle$ SDM_Historical (1911 \& $1984-1999)$

PC $1(23 \%)$

Fig. 2. Principal coordinate analysis of pairwise genotypic distance between 232 Plasmopara halstedii historical and modern samples from Helianthus spp. (sunflower; SDM) and Rudbeckia spp. (rudbeckia; RDM) downy mildew samples. The first two principal coordinates are shown. Samples are coded by the shape of the data point (triangle $=$ sunflower host; circle $=$ rudbeckia host) and the color (historical samples = open triangles/circles; modern samples $=$ full color).
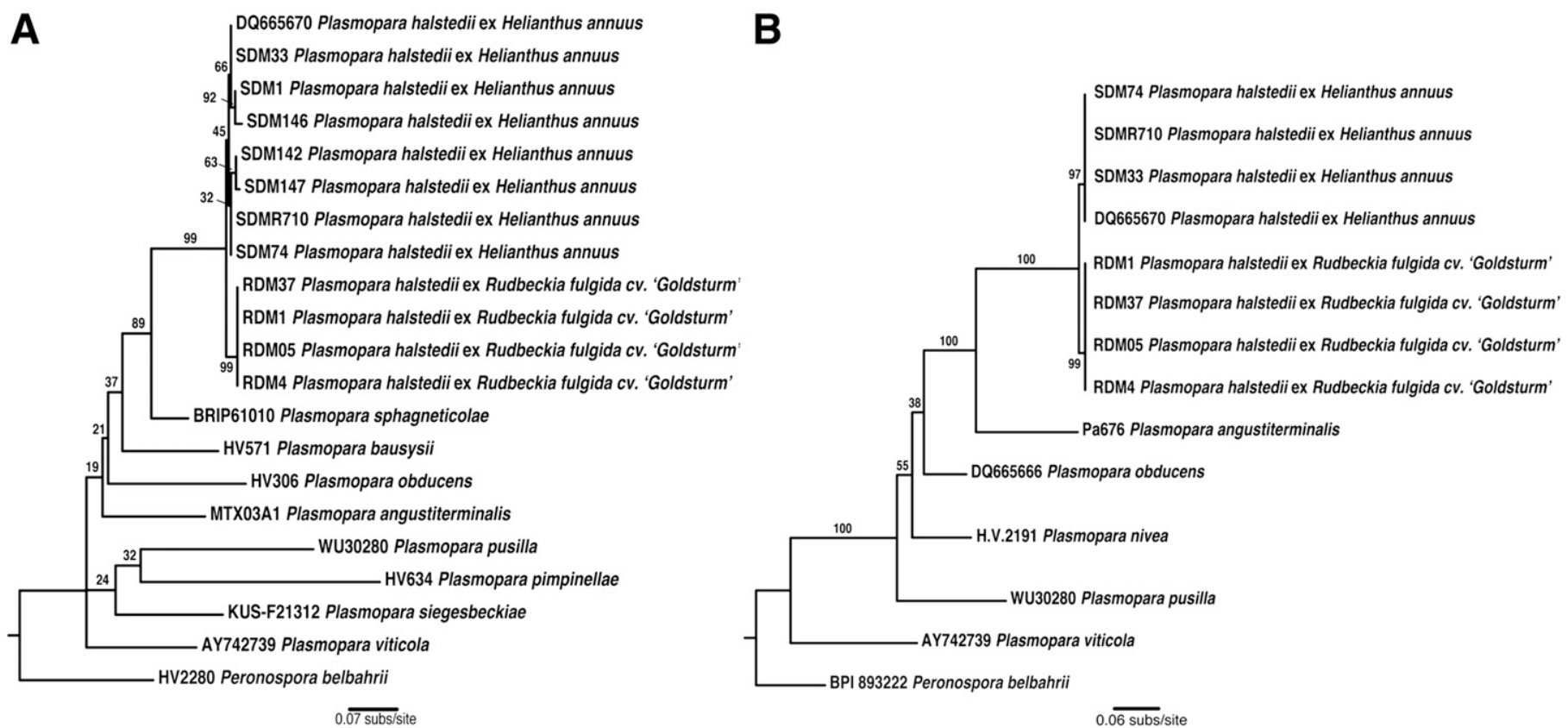

Fig. 3. Maximum likelihood best trees for A, cox2 and $\mathbf{B}$, rDNA internal transcribed spacer regions. Bootstrap values are indicated at branches (1,000 replicates). Scale represents expected number of changes per site. Both trees were outgroup rooted with Peronospora belbahrii. 
lato on multiple Asteraceae hosts have coexisted in space and time. Given this, an evolutionary pattern of cospeciation between host and pathogen would be expected. However, recent work in Bremia suggests that host shifts followed by radiation and speciation may better explain the diversity and evolution of downy mildew pathogens (Choi and Thines 2015). Similar conclusions were drawn from studies of the grape downy mildew pathogen $P$. viticola, where host range expansion from wild to cultivated grapes in North America led to an increase in pathogen aggressiveness (Rouxel et al. 2013). Such a scenario of host range expansion followed by diversification would also be consistent with our observations of $P$. halstedii population structure on sunflower and rudbeckia. Sympatric diversification of $P$. halstedii between the two plant genera may have been a result of an increased cultivation and hybrid selection of both sunflower and rudbeckia. This diversification could have resulted in a host range expansion and specialization of modern populations, initially resulting in host shifts from sunflower onto native Rudbeckia spp. populations, and more recently leading to the outbreaks of downy mildew disease on cultivated $R$. fulgida.

The rapid evolution of downy mildew pathogens coupled with the lack of accurate species classification and knowledge of host range leaves global agricultural systems at risk and challenges global agricultural trade. The examination of the genetic diversity in historical and modern samples of $P$. halstedii presented in our study emphasizes the importance of downy mildews as emergent pathogens. The results of this research may provide critical information for plant breeding and disease management programs in the ornamental horticulture and sunflower industries.

\section{ACKNOWLEDGMENTS}

We thank J. Byrne, D. Clement, T. Creswell, M. Daughtrey, S. Jensen, K. Snover-Clift, R. Leatherwood, C. Misar, R. Peterman, L. Pundt, K. Rane, M. Romberg, and A. Windham for providing fresh samples of $P$. halstedii on sunflower and rudbeckia; N. Saied, C. Misar, and M. Gilley for technical support; S. Sheffer and M. Lewis for the use of the ABI 3730xl instrument; and the U.S. National Fungus Collection for allowing access to herbarium specimens. We are particularly indebted to A. Gould for her continued partnership and support, and for her ongoing mentorship of Y. Rivera and C. Salgado-Salazar. This research was funded by a 2013 USDA-APHISPPQ Farm Bill grant to JAC and USDA-ARS project 8042-22000-279; Y. Rivera and C. Salgado-Salazar were supported by 2013-2015 USDAAPHIS-PPQ Farm Bill grants to J. A. Crouch. Mention of trade names or commercial products in this publication is solely for the purpose of providing specific information and does not imply recommendation or endorsement by the U.S. Department of Agriculture. The USDA is an equal opportunity provider and employer.

\section{LITERATURE CITED}

Ahmed, S., de Labrouhe, D. T., and Delmotte, F. 2012. Emerging virulence arising from hybridisation facilitated by multiple introductions of the sunflower downy mildew pathogen Plasmopara halstedii. Fungal Genet. Biol. 49:847-855.

Akaike, H. 1974. A new look at the statistical model identification. IEEE Trans. Automat. Contr. 19:716-723.

Altschul, S., Gish, W., and Miller, W. 1990. Basic Local Alignment Search Tool. J. Mol. Biol. 215:403-410.

As-sadi, F., Carrere, S., Gascuel, Q., Hourlier, T., Rengel, D., Le Paslier, M. C., Bordat, A., Boniface, M. C., Brunel, D., Gouzy, J., Godiard, L., and Vincourt, P. 2011. Transcriptomic analysis of the interaction between Helianthus annuиs and its obligate parasite Plasmopara halstedii shows single nucleotide polymorphisms in CRN sequences. BMC Genomics 12:498.

Callaghan, S., and Guest, D. 2015. Globalisation, the founder effect, hybrid Phytophthora species and rapid evolution: New headaches for biosecurity. Australas. Plant Pathol. 44:255-262.

Choi, Y. J., Beakes, G., Glockling, S., Kruse, J., Nam, B., Nigrelli, L., Ploch, S., Shin, H. D., Shivas, R. G., Telle, S., Voglmayr, H., and Thines, M. 2015. Towards a universal barcode of oomycetes-A comparison of the coxl and cox2 loci. Mol. Ecol. Resour. 15:1275-1288.

Choi, Y. J., Kiss, L., Vajna, L., and Shin, H. D. 2009. Characterization of a Plasmopara species on Ambrosia artemisiifolia, and notes on P. halstedii, based on morphology and multiple gene phylogenies. Mycol. Res. 113: 1127-1136.

Choi, Y. J., and Thines, M. 2015. Host jumps and radiation, not co-divergence drives diversification of obligate pathogens. A case study in downy mildews and Asteraceae. PLoS One 10:e133655.

Cohen, Y., Van den Langenberg, K. M., Wehner, T. C., Ojiambo, P. S., Hausbeck, M., Quesada-Ocampo, L. M., Lebeda, A., Sierotzki, H., and Gisi, U. 2015. Resurgence of Pseudoperonospora cubensis: The causal agent of cucurbit downy mildew. Phytopathol. 105:998-1012.

Constantinescu, O., and Thines, M. 2010. Plasmopara halstedii is absent from Australia. Pol. Bot. J. 55:293-298.

Crouch, J. A., Ko, M. P., and McKemy, J. M. 2013. First report of impatiens downy mildew outbreaks caused by Plasmopara obducens throughout the Hawai'ian Islands. Plant Dis. 98:696.

Dankers, H., Kimbrough, J. W., and Momol, M. T. 2004. First report of Plasmopara halstedii on perennial black-eyed Susan in North Florida. Published online. Plant Health Progress.

Darriba, D., Taboada, G. L., Doallo, R., and Posada, D. 2012. jModelTest 2: More models, new heuristics and parallel computing. Nat. Methods 9:772.

Daughtrey, M. L., Holcomb, G. E., Eshenaur, B., Palm, M. E., Belbahri, L., and Lefort, F. 2006. First report of downy mildew on greenhouse and landscape coleus caused by a Peronospora sp. in Louisiana and New York. Plant Dis. 90:1111.

Delmotte, F., Chen, W. J., Richard-Cervera, S., Greif, C., Papura, D., Giresse, X., Mondor-Genson, G., and Corio-Costet, M. F. 2006. Microsatellite DNA markers for Plasmopara viticola, the causal agent of downy mildew of grapes. Mol. Ecol. Notes 6:379-381.

Delmotte, F., Giresse, X., Richard-Cervera, S., M'baya, J., Vear, F., Tourvieille, J., Walser, P., and deLabrouhe, D. T. 2008. Single nucleotide polymorphisms reveal multiple introductions into France of Plasmopara halstedii, the plant pathogen causing sunflower downy mildew. Infect. Genet. Evol. 8:534-540.

Duarte, L., Choi, C., Soares, D. J., and Barreto, R. W. 2014. Plasmopara invertifolia sp. nov. causing downy mildew on Helichrysum bracteatum (Asteraceae). Mycol. Prog. 13:285-289.

Earl, D. A., and vonHoldt, B. M. 2012. STRUCTURE HARVESTER: A website and program for visualizing STRUCTURE output and implementing the Evanno method. Conserv. Genet. Resour. 4:359-361.

Evanno, G., Regnaut, S., and Goudet, J. 2005. Detecting the number of clusters of individuals using the software STRUCTURE: A simulation study. Mol. Ecol. 14:2611-2620.

Falush, D., Stephens, M., and Pritchard, J. K. 2003. Inference of population structure using multilocus genotype data: Linked loci and correlated allele frequencies. Genetics 164:1567-1587.

Falush, D., Stephens, M., and Pritchard, J. K. 2007. Inference of population structure using multilocus genotype data: Dominant markers and null alleles. Mol. Ecol. Notes 7:574-578.

Farlow, W. G. 1883. Notes on some species in the third and eleventh centuries of Ellis's North American Fungi. Proc. Am. Acad. Arts Sci. 18:65-85.

Farr, D. F., and Rossman, A. Y. 2015. Fungal Databases. Systematic Mycology and Microbiology Laboratory, ARS-USDA.

Gascuel, Q., Martinez, Y., Boniface, M. C., Vear, F., Pichon, M., and Godiard, L. 2015. The sunflower downy mildew pathogen Plasmopara halstedii. Mol. Plant Pathol. 16:109-122.

Göker, M., Voglmayr, H., Riethmüller, A., and Oberwinkler, F. 2007. How do obligate parasites evolve? A multi-gene phylogenetic analysis of downy mildews. Fungal Genet. Biol. 44:105-122.

Guindon, S., and Gascuel, O. 2003. A simple, fast, and accurate algorithm to estimate large phylogenies by maximum likelihood. Syst. Biol. 52: 696-704.

Gulya, T. J. 1996. Everything you should know about downy mildew testing but were afraid to ask. Pages 39-48 in: Proc. 18th Sunflower Research Workshop. Nat. Sunflower Assoc., Mandan, ND. http://www.sunflowernsa. com/uploads/research/639/1996_gulya_everythingdowny.pdf

Gulya, T. J. 2002. First report of cross-infectivity of Plasmopara halstedii from marshelder to sunflower. Plant Dis. 86:919.

Gulya, T. J., Due, B., and Hutter, M. 2010. New virulent races of downy mildew. Proc. Sunflower Res. Forum. Nat. Sunflower Assoc., Mandan, ND. http://www.sunflowernsa.com/uploads/resources/171/gulya1_virulentraces_10.pdf

Gulya, T. J., Kandel, H. M., Maselen, M., Knodel, J., Berglund, D., Mathew, F., Lamey, A., Nowatski, J., and Markell, S. 2013. Prevalence and incidence of sunflower downy mildew in North Dakota between 2001 and 2011. Published Online. Plant Health Progress. doi:10.1094/PHP-2013-0522-01-RS.

Gulya, T. J., Masirevic, S., and Thomas, C. E. 1993. Preservation of air-dried downy mildew without cryoprotectants or controlled freezing. Mycol. Res. 97:240-244.

Gulya, T. J., Miler, J. F., Virányi, F., and Sackston, W. E. 1991. Proposed internationally standardized method for race identification of Plasmopara halstedii. Helia 14:11-20. 
Gulya, T. J., Rashid, K. Y., and Masirevic, S. M. 1997. Sunflower Diseases. Pages 263-379 in: Sunflower Technology and Production. A. A. Schneiter, ed. American Society of Agronomy, Madison, WI.

Hong, C. X. 2006. Downy mildew of Rudbeckia fulgida cv. "Goldsturm" by Plasmopara halstedii in Virginia. Plant Dis. 90:1461.

Hubisz, M. J., Falush, D., Stephens, M., and Pritchard, J. K. 2009. Inferring weak population structure with the assistance of sample group information. Mol. Ecol. Resour. 9:1322-1332.

Hudspeth, D. S. S., Nadler, S. A., and Hudspeth, M. E. S. 2000. A cox2 molecular phylogeny of the Peronosporomycetes. Mycologia 92:674-684.

Kamvar, Z. N., Tabima, J. F., and Grünwald, N. J. 2014. Poppr: An R package for genetic analysis of populations with clonal, partially clonal, and/or sexual reproduction. PeerJ 2:e281.

Komjáti, H., Walcz, I., Virányi, F., Zipper, R., Thines, M., and Spring, O. 2007. Characteristics of a Plasmopara angustiterminalis isolate from Xanthium strumarium. Eur. J. Plant Pathol. 119:421-428.

Kopelman, N., Mayzel, J., Jakobsson, M., Rosenberg, N., and Mayrose, I. 2015. CLUMPAK: A program for identifying clustering modes and packaging population structure inferences across K. Mol. Ecol. Resour. 15:1179-1191.

Leppik, E. 1965. Plasmopara halstedii and other diseases on Dimorphotheca. Plant Dis. Rep. 49:940-942.

Leppik, E. 1966. Origin and specialization of Plasmopara halstedii complex on the Compositae. FAO Plant Prot. Bull. 14:72-76.

McTaggart, A. R., Shuey, L. S., McKenna, S. G., Davis, R. I., and Shivas, R. G. 2015. Plasmopara sphagneticolae sp. nov. (Peronosporales) on Sphagneticola (Asteraceae) in Australia. Australas. Plant Pathol. 44:81-85.

Moncalvo, L., Wang, H., and Hseu, R. 1995. Phylogenetic relationships in Ganoderma inferring from the internal transcribed spacers and $25 \mathrm{~S}$ ribosomal DNA sequences. Mycologia 87:223-238.

Peakall, R., and Smouse, P. E. 2012. GenAlEx 6.5: Genetic analysis in Excel. Population genetic software for teaching and research-an update. Bioinformatics 28:2537-2539.

Pritchard, J. K., Stephens, M., and Donnelly, P. 2000. Inference of population structure using multilocus genotype data. Genetics 155:945-959.

Rambaut, A. 2009. FigTree version 1.3.1. Available online. http://tree.bio.ed. ac.uk/software/figtree/

Rivera, Y., Creswell, T. C., Ruhl, G., and Crouch, J. A. 2015a. First report of downy mildew caused by Plasmopara halstedii on native Rudbeckia fulgida Aiton var. speciosa (Wender.) Perdue in Indiana. Plant Dis. 99:1278.

Rivera, Y., Rane, K., and Crouch, J. A. 2014. First report of downy mildew caused by Plasmopara halstedii on black-eyed Susan (Rudbeckia fulgida cv. 'Goldsturm') in Maryland. Plant Dis. 98:1005.

Rivera, Y., Salgado-Salazar, C., Creswell, T., Ruhl, G., and Crouch, J. A. 2015b. First report of downy mildew caused by Peronospora sp. on Agastache sp. in the United States. Plant Dis. doi:10.1094/PDIS-10-15-1119-PDN

Rivera, Y., Salgado-Salazar, C., Windham, A., and Crouch, J. A. 2016. Downy mildew on coleus (Plectranthus scutellarioides) caused by Peronospora belbahrii sensu lato in Tennessee. Plant Dis. 100:655.

Roeckel-Drevet, P., Tourvieille, J., Gulya, T. J., Charmet, G., Nicolas, P., and deLabrouhe, D. T. 2003. Molecular variability of sunflower downy mildew, Plasmopara halstedii, from different continents. Can. J. Microbiol. 49: 492-502.

Rossman, A. 1996. The evolution of fungal diversity. Pages 33-39 in: Microbial Diversity in Time and Space. R. R. Colwell, U. Simidu, and K. Ohwada, eds. Springer.

Rouxel, M., Mestre, P., Comont, G., Lehman, B. L., Schilder, A., and Delmotte, F. 2013. Phylogenetic and experimental evidence for host-specialized cryptic species in a biotrophic oomycete. New Phytol. 197:251-263.
Sackston, W. E. 1981. Downy mildew of sunflower. Pages 545-575 in: The Downy Mildews. D. M. Spencer, ed. Academic Press, London, UK.

Salgado-Salazar, C., Rivera, Y., Veltri, D., and Crouch, J. A. 2015. Polymorphic SSR markers for Plasmopara obducens (Peronosporaceae), the newly emergent downy mildew pathogen of Impatiens (Balsaminaceae). Appl. Plant Sci. 3:1500073.

Schröder, S., Telle, S., Nick, P., and Thines, M. 2011. Cryptic diversity of Plasmopara viticola (Oomycota, Peronosporaceae) in North America. Org. Divers. Evol. 11:3-7.

Schuelke, M. 2000. An economic method for the fluorescent labeling of PCR fragments. Nat. Biotechnol. 18:233-234.

Silvestro, D., and Michalak, I. 2012. RaxmlGUI: A graphical front-end for RAxML. Org. Divers. Evol. 12:335-337.

Spring, O., Bachofer, M., Thines, M., Riethmüller, A., Göker, M., and Oberwinkler, F. 2006. Intraspecific relationship of Plasmopara halstedii isolates differing in pathogenicity and geographic origin based on ITS sequence data. Eur. J. Plant Pathol. 114:309-315.

Spring, O., Voglmayr, H., Riethmüller, A., and Oberwinkler, F. 2003. Characterization of a Plasmopara isolate from Helianthus $\times$ laetiflorus based on cross infection, morphological, fatty acids and molecular phylogenetic data. Mycol. Prog. 2:163-170.

Stamatakis, A. 2006. RAxML-VI-HPC: Maximum likelihood-based phylogenetic analyses with thousands of taxa and mixed models. Bioinformatics 22:2688-2690.

Thiel, T., Michalek, W., Varshney, K., and Graner, A. 2003. Exploiting EST databases for the development and characterization of gene-derived SSRmarkers in barley (Hordeum vulgare L.). Theor. Appl. Genet. 106:411-422.

Thines, M. 2014. Phylogeny and evolution of plant pathogenic oomycetes-a global overview. Eur. J. Plant Pathol. 138:431-447.

Thines, M., Göker, M., Telle, S., Ryley, M., Mathur, K., Narayana, Y. D., Spring, O., and Thakur, R. P. 2008. Phylogenetic relationships of graminicolous downy mildews based on $\operatorname{cox} 2$ sequence data. Mycol. Res. 112: 345-351.

Thines, M., Telle, S., Ploch, S., and Runge, F. 2009. Identity of the downy mildew pathogens of basil, coleus, and sage with implications for quarantine measures. Mycol. Res. 113:532-540.

Tourvieille, D., Lafon, S., Walser, P., and Raulic, I. 2000. Une nouvelle race de Plasmopara halstedii, agent du mildiou du tournesol. Oleagineux 7: 404-405.

Untergasser, A., Cutcutache, I., Koressaar, T., Ye, J., Faircloth, B. C., Remm, M., and Rozen, S. G. 2012. Primer3-new capabilities and interfaces. Nucleic Acids Res. 40:1-12.

Verkley, G. M., Rossman, A., and Crouch, J. 2015. The role of herbaria and culture collections. Pages 205-225 in: Systematics and Evolution, The Mycota. J. D. McLaughlin and J. W. Spatafora, eds. Springer, Berlin, Heidelberg.

Viranyi, F. 1984. Recent research on the downy mildew of sunflower in Hungary. Helia 7:35-38.

Voglmayr, H., Riethmüller, A., Göker, M., Weiss, M., and Oberwinkler, F. 2004. Phylogenetic relationships of Plasmopara, Bremia and other genera of downy mildew pathogens with pyriform haustoria based on Bayesian analysis of partial LSU rDNA sequence data. Mycol. Res. 108:1011-1024.

Walcz, I., Bogár, K., and Virányi, F. 2000. Study on an Ambrosia isolate of Plasmopara. Helia. 23:19-24.

Yoshida, K., Schuenemann, V. J., Cano, L. M., Pais, M., Mishra, B., Sharma, R., Lanz, C., Martin, F. N., Kamoun, S., and Krause, J. 2013. The rise and fall of the Phytophthora infestans lineage that triggered the Irish potato famine. eLife 2:e0731. 